\title{
Antecedentes coloniales de la economía colombiana ${ }^{\mathrm{A}}$
}

\section{Germán Colmenares ${ }^{B}$}

Hasta hace poco tiempo prácticamente se concebía que los hombres de Colón habían visto surgir delante suyo un continente vacío. La historiografía proyectaba una especie de film en el cual la aventura humana solo comenzaba con la intervención del hombre civilizado. A partir de este momento la "realidad" del Nuevo Mundo ha dependido en mucho de su imagen proyectada en la mente del hombre europeo ${ }^{1}$. Nada ha sido más persistente que esa imagen y no se ha ahorrado esfuerzo para reconstruir todos sus detalles. La historia del "Descubrimiento" se acompaña minuciosamente con la historia de los presentimientos y de la "invención" de América. América vista, naturalmente, desde fuera.

A En La Nueva Economía, t. V, n. ${ }^{\circ}$ 1, abril de 1969. La indicación bibliográfica ha sido escrita encima del texto, en la parte superior de la primera página de la copia de que disponemos, por Hernán Lozano, editor de la llamada "Obra Completa" de Germán Colmenares. Se trata de un artículo de revista poco conocido y que muestra una faceta de Colmenares como historiador de "síntesis", aún en búsqueda de los propios resultados de su trabajo. Una nota escrita por el mencionado Hernán Lozano, que formaba parte de sus apuntes sobre los textos de Colmenares que leía y con los que intentaba familiarizarse, trata de caracterizar este artículo. Dice Lozano: "Notable abundancia de referencias a fuentes secundarias y escasa a documentos de archivo. Visión general que llega hasta mediados del siglo XIX. Proposiciones provocadoras sobre puntos problemáticos: 'La leyenda negra ha escapado de su marco teológico y político para asumir un aspecto más prosaico'. 'El verdadero «Eldorado» [consistió] en la existencia de sociedades de una cierta amplitud cuyos excedentes económicos podían usufructuarse a perpetuidad'. Encomienda, resguardo y mita. El sistema económico no feudal. La conquista, empresa privada. Las leyes de 1542 implicaban 'eliminar a la base de sustentación de los pobladores blancos'. La esclavitud, la minería, la singularidad antioqueña”. Hay que corregir un tanto la apreciación de Hernán Lozano: en realidad las fuentes primarias son muchísimas, solo que algunas las toma Colmenares de compilaciones ya publicadas, como las de Juan Friede, que citó y elogio muchas veces, mientras que otras se apoyan en su propia investigación de archivo, fuentes que no enumera una por una, aunque cita su trabajo Fuentes Coloniales para la Historia del Trabajo en Colombia (Bogotá: Universidad de los Andes, 1968), constituido precisamente por transcripciones de fuentes primarias. El presente dossier incluye las páginas de presentación de esa compilación de fuentes. Por lo demás, es clara la presencia en el texto de fondos del actual AGN-Colombia, como "Tierras "o "Visitas", para citar dos ejemplos de repositorios que fueron de uso sistemático por parte de Colmenares. Señalemos además que las tesis que menciona Hernán Lozano como novedosas, tenían cierta novedad en Colombia, pero eran viejas conocidas de la mejor historiografía latinoamericana. Otras constituyen ideas - o hipótesis - que Colmenares mantuvo y precisó en los veinte años siguientes. El texto es de mucho interés, si se le sabe localizar en su contexto historiográfico y en la evolución del autor.

B Profesor de la Universidad de los Andes [se lee al lado del nombre del autor].

1 Un trabajo de Edmundo O’Gorman plantea la pregunta de cuándo y cómo aparece América en la conciencia histórica. Cierto refinamiento escolástico puede muy bien suponer que “... el ser de América es un suceso dependiente de la forma de su aparición...” en la conciencia europea. Esta manera de ver las cosas no modifica los hechos, aunque quiera subrayar el papel activo de la conciencia europea en el vacuum [vacío] americano. Cf. [E. O’Gorman] La invención de América (el universalismo de la cultura de Occidente) (México: 1958), 90 y ss. 
Esta invención, sin embargo, tropieza con algunos obstáculos. El continente poseía una corporeidad, que era imposible suprimir para encontrar la ruta de las Indias orientales. Luego, no era un continente vacío en el cual las hazañas de los conquistadores pudieran desplegarse como un mero espectáculo. El paso de los conquistadores en pos de hipotéticos "Eldorados" no significó precisamente la creación de un mundo, sino la destrucción de uno que ya existía. En términos más concretos, la irrupción del mundo capitalista occidental en el ámbito de las culturas aborígenes americanas desencadenó un fenómeno particularmente adverso desde el punto de vista de la historia económica. Una verdadera catástrofe demográfica que, para las costas de "Tierra Firme", puede medirse a partir de un hipotético 1500 (en el que la población estaría intacta) y que se prolongaría hasta $1650^{2}$. A pesar de la importancia de este hecho, apenas ahora comienzan a hacerse evidentes, mediante cálculos acuciosos, todas sus complejas implicaciones. La revaloración de las llamadas "culturas primitivas" ha contribuido a arrojar una luz nueva sobre el valor que puede atribuirse a la incorporación de América al mundo civilizado. Al menos el hecho demográfico obliga a plantearse la cuestión desde una nueva perspectiva. Cuando se avanzan cálculos de millones para la primitiva población de los territorios americanos ${ }^{3}$ (anteriormente una cierta pudibundez racionalista avanzaba tímidamente algunos miles) se problematiza el sentido entero de esta incorporación.

El escepticismo que solía rodear a la iracundia del Padre de Las casas respecto a las cifras "fabulosas" en que calculaba la mortandad indígena en las islas del Caribe ha dado lugar a una reflexión detallada sobre las causas que provocaron esta catástrofe demográfica. La "Leyenda Negra" ha escapado de su marco teológico y político para asumir un aspecto más prosaico. Si se miden las condiciones de la vida material que hacían posible la existencia de millones de hombres y enseguida se comparan esas condiciones con las que hizo surgir, en sustitución, el sistema europeo transplantado al nuevo continente, se está frente a un complejo problema de cambio de estructuras políticas, sociales y económicas.

En un sentido, sin embargo, el cambio de sistema no fue tan absoluto como pudiera pensarse. En el caso de imperios aborígenes organizados se operó apenas una superposición que ilustra materialmente el trazo y la arquitectura de la ciudad de Cuzco. El verdadero "Eldorado" no consistió en la acumulación de metales preciosos que podía expoliarse con facilidad sino en la existencia de sociedades de una cierta

2 La presión sobre la población nativa comenzó desde el momento mismo en que Juan de la Cosa recibió prácticamente una autorización de la corona española para capturar como esclavos a los indios de "Tierra Firme", supuestamente caníbales, en 1503. Cf. Carl Ortwin Sauer, The Early Spanish Main (Berkeley: 1966), 161 y ss.

3 Los cálculos cuidadosos llevados a cabo por los investigadores norteamericanos Cook, Simpson y Borah para México han abierto la posibilidad de revisar las cifras que se basan en la deficiente observación de los cronistas y aprovechar mediante una metodología adecuada, fuentes de información excepcionalmente ricas. 
amplitud cuyos excedentes económicos podían usufructuarse a perpetuidad. Por eso la extinción de la sociedad indígena significó la pérdida definitiva e irremediable del conquistador.

Las primeras operaciones españolas en el territorio de la Nueva Granada tuvieron lugar con los saqueos de Alonso de Ojeda y Cristóbal Guerra de las costas de "Tierra Firme", desde 1500 hasta 1502. A fines de 1509 surgieron establecimientos permanentes al noroeste de la actual Colombia, en Panamá y el Darién, llamados desde entonces propiamente "Tierra Firme", a raíz de la profunda crisis experimentada por los asentamientos españoles de las islas. Hasta entonces las correrías de los españoles habían sido simplemente "razzias" encaminadas a capturar indígenas que serían vendidos como esclavos en las Antillas, para compensar las pérdidas vertiginosas de la población de las islas, transformadas muy pronto en colonias mineras y después de 1517 en ingenios azucareros. Pero el surgimiento de una "colonia" no hizo variar fundamentalmente la situación, sino que simplemente desplazó un centro de operaciones por otro. Los ocupantes españoles del Darién siguieron organizando "cabalgadas" esclavistas cuyos rendimientos pagaban sus consumos de artículos de origen europeo. Esta situación se prolongó hasta la década del 30 cuando el descubrimiento del Perú atrajo poderosamente a los aventureros españoles ${ }^{4}$.

El descubrimiento de México, que cerraba la supuesta ruta hacia las Indias Orientales, y la incertidumbre de las distancias geográficas, que aproximaba intuitivamente las riquezas del fabuloso Perú, prepararon el ánimo de los conquistadores hacia nuevas empresas. Pues estas implicaban una preparación sicológica tanto como económica.

Ante todo, había que procurarse enclaves destinados a proporcionar las vituallas necesarias para la penetración. Aunque su primitivo carácter fuera el de constituir un centro más de "cabalgadas", la ciudad de Santa Marta jugó este papel debido a su situación excepcional, muy cerca de las desembocaduras del Río Grande de la Magdalena, que penetraba en el corazón del país. De allí partió, en abril de 1536, la expedición que había de ascender a las planicies de Bogotá y Tundama un año después.

La historiografía tradicional se complace en la imagen heroica de la conquista casi en la misma medida en que especula sobre la cuantía de los objetos obtenidos ${ }^{5}$. Por eso parece casi inoportuno insistir en el carácter pacífico de la mayoría de las tribus sojuzgadas. Además, el llamado "primer ciclo del oro" se agotó muy rápidamente.

4 Sobre este primer periodo, además de los clásicos relatos de Las Casas y Fernández de Oviedo, existe una documentación adecuada en la colección de Juan Friede, Documentos inéditos para la Historia de Colombia, vol. I. y II (Bogotá: 1955). La fisonomía de las empresas de Panamá y el Darién está descrita en un trabajo del chileno Mario Góngora. Los grupos de conquistadores de Tierra Firme (1509-1530) (Santiago: 1962). También los capítulos VIII, XI y XIII de la obra citada de Sauer.

5 La exactitud documental de un trabajo reciente de Juan Friede, Invasión del país de los chibchas (Bogotá: 1966), contribuye a desvanecer los excesos imaginativos con que se ha solido rodear esta empresa. 
Las cantidades de metales preciosos acumulados por las poblaciones indígenas apenas bastaron para financiar parte de las empresas de ocupación. De otro lado, los trabajos en minas de aluvión, en los que se emplearon trabajadores indígenas, o agotaron los veneros, o repitieron la experiencia antillana, exterminando tan rápidamente la población nativa, que vinieron a crear serios problemas de abastecimientos para las nuevas fundaciones.

Pero la mano de obra gratuita, que podía emplearse en la agricultura mediante la coacción, y las mismas economías indígenas, capaces de crear excedentes, ofrecían posibilidades al parecer inagotables. Los cálculos sobre la población aborigen del interior del país en el momento de la conquista, particularmente aquella de las regiones económicamente significativas, es decir los altiplanos indígenas densamente poblados, son todavía escasos y casi todos parecen inseguros ${ }^{6}$. Y aunque es evidente el descenso vertiginoso que se operó a partir de la penetración española y que se prolongó hasta mucho después, los resultados de una simple extrapolación estadística a partir de datos conocidos parecen increíbles.

Como quiera que sea, la estructura económica impuesta por la conquista y la colonización españolas estuvo sujeta en todo su desarrollo a un hecho casi fatal. Con el agravante de que en la Nueva Granada la población aborigen jamás se recuperó, como parece haber ocurrido en otras regiones del Imperio español.

Puede decirse que la colonia jamás conoció la prosperidad ${ }^{7}$. En sus orígenes (a partir de 1540) la presencia de una civilización pacificada, que disponía de una economía de cierta amplitud, permitió la superposición de pobladores españoles. Esta se realizó mediante el régimen de la "encomienda".

Según la intención de la corona española esta institución, fuertemente teñida de rasgos paternalistas, tenía por objeto la conversión de los indígenas al cristianismo. El encomendero tenía como obligación procurar esta conversión sosteniendo un doctrinero y adecuando un lugar para el culto. En cambio podía gozar de los tributos indígenas, de los cuales participaba un "quinto" a la corona. Pero este sistema de prestaciones mutuas que estipulaba cada título otorgado tiene escasamente que ver con la institución. Por lo demás, es fácil imaginar como operaba en la práctica.

6 La obra ya clásica de [Ángel] Rosemblat asigna 840000 almas al Nuevo Reino. Sin embargo, las bases de esta afirmación son las mismas que los trabajos de Borah y Cook han desvirtuado para México. Una monografía reciente de Jaime Jaramillo Uribe, "La población indígena de Colombia en el momento de la conquista y sus transformaciones posteriores", Anuario Colombiano de Historia Social y de la Cultura (1963), insiste en esta cifra. Los trabajos de Juan Friede, más cautos, basados en información documental cuidadosa, permitirían avanzar cifras superiores.

7 Compárense, por ejemplo, las cifras deducidas por Chaunu para el tráfico de los puertos americanos. $C f$. Pierre Chaunu, Séville et l'Atlantique (1504-1850) (Paris: 1955), especialmente el anexo de gráficos en donde se puede apreciar claramente cómo la importancia de Nombre de Dios y Porto Belo, puntos de tránsito obligado para el Perú, crece en una proporción de 10:1 sobre Cartagena, excepto para el periodo muy corto de 1591-1630, debido al tráfico de esclavos. 
Un encomendero recibía en "repartimiento" - como premio por sus servicios a la corona, es decir, en calidad de conquistador, pacificador, fundador o primer poblador - un número de indios que fluctuaba entre 500 y 2000 en regiones densamente pobladas, o de 100 a 500 en lugares en donde las comunidades indígenas estaban muy esparcidas. De estos disponía de la población masculina - los llamados "tributarios" de 15 a 60 años - prácticamente a su antojo. Podía dedicarles a trabajos en las minas, a labores agrícolas o a servicios domésticos. Las prohibiciones en este sentido eran meramente formales, puesto que a las numerosas excepciones se sumaba la inocuidad de las sanciones ${ }^{8}$.

Si bien la corona se esforzó por señalar una mera participación pecuniaria de parte de los indígenas para exonerarlos de toda otra obligación con respecto a los encomenderos, la escasez de numerario y el carácter ficticio de los salarios permitieron siempre al encomendero disponer de esta mano de obra prácticamente gratuita. Por otra parte, cada título de encomienda - con muy pocas excepciones - estipulaba que el "repartimiento" no incluía las tierras de los indígenas, antes bien, se encargaba al encomendero velar por su integridad. Sin embargo, la inserción de un sistema económico monetario, en un medio que difícilmente podía adoptarlo, la introducción de ganado y la despoblación vertiginosa, además del pago de tributos - que casi siempre se hizo en especie: oro, maíz, mantas, etc.-, subordinaron íntegramente los sistemas tradicionales de vida y explotación económica a los nuevos amos.

No puede decirse, en cambio, que con ese sistema, los indígenas hayan recibido una compensación siquiera retórica. La introducción de implementos técnicos o la tracción animal apenas beneficiaron los cultivos europeos - trigo, cebada — o los intentos de plantaciones - caña de azúcar, tabaco - que ocupaban tres o cuatro meses del año a la población encomendada y, por consiguiente, tendían más bien a reducir cada vez más los cultivos indígenas de maíz, cuyos rendimientos por hectárea eran mucho mayores. El ganado también constituyó un elemento perturbador de la subsistencia indígena, pues sólo a finales del siglo XVI se aplicó una política de demarcación de tierras para los indígenas, política conocida con el nombre de "resguardos". Pero aun después fueron muy frecuentes las quejas por devastaciones de los ganados de españoles en cultivos indígenas.

Un esquema conceptual europeo ha querido asimilar este este sistema señorial al feudalismo. En realidad no se trataba de nada semejante desde el punto de vista económico, aunque tuviera parecidas implicaciones políticas, $\mathrm{y}$ especialmente sociales.

8 En numerosos expedientes consultados figuran, en efecto, cargos contra los encomenderos por abusar del trabajo de los indígenas. Pero los testimonios de descargo provenían de otros encomenderos y al final la situación se resolvía en una sanción pecuniaria que dependía más bien de la magnitud de la encomienda que de la gravedad de los cargos.

9 Sobre la evolución de los resguardos en la Nueva Granada véase el capítulo que dedica Orlando Fals Borda — El Hombre y la tierra en Boyacá (Bogotá: 1957) — a este problema. 
En tanto que el sistema europeo medieval significó el atrofiamiento de una economía originalmente urbana, el encomendero fue un elemento urbano por excelencia, un "poblador" y la encomienda una sistema de organización del trabajo indígena vinculado al abastecimiento de las ciudades. En el peor de los casos, el abastecimiento del mismo encomendero dentro de la ciudad. Podría mencionarse también la existencia de un salario, siquiera fuera nominal. Los pagos en especie permitían al menos la circulación de productos artesanales — textiles principalmente - con que los indios satisfacían sus tributos.

Políticamente, en cambio, la tendencia natural del conquistador pugnaba por hacer lo más tenues posible los vínculos con el Estado español, pues toda la empresa de la conquista se había financiado con recursos privados. Además, en presencia de pueblos a los que se sometía con relativa facilidad, existía una tentación permanente de tallarse un imperio o desoír las advertencias de funcionarios reales puntillosos.

La nueva sociedad asentada sobre los privilegios de los "conquistadores", tendía a estratificarse muy rápidamente. Los primeros "vecinos", entre los cuales se habían hecho "repartimientos" de tierras y de indios, gozaban así mismo, a través de los cabildos y de otros cargos, de una cuota de poder político. El bien del "común" se identificaba fácilmente con sus propios intereses. Estos aun podían neutralizarse entre sí, siempre y cuando la presencia de un caudillo prestigioso no impusiera sus propias pretensiones. Estas chocaban con el interés del Estado español, pues eran difícilmente controlables estando el océano de por medio.

Por eso, la tentativa de abolir las fuerzas centrífugas dentro de las nuevas posesiones mediante leyes especialmente severas, en 1542, condujo a sobresaltos en las colonias. La Corona se propuso abolir la perpetuación del poder de los encomenderos y para ello estableció reglas de sucesión, limitando a dos vidas el usufructo de este privilegio. Por otra parte, creó incompatibilidades, cercenando en cierta forma el poder político de los encomenderos. Los conquistadores que gozaban de repartimiento de indios reaccionaron vivamente en México y en el Perú. La supresión del sistema de la encomienda significaba, según ellos, eliminar la base de sustentación de los pobladores blancos. Acaso tuvieran razón, dadas las condiciones de las formas sociales que surgieron a raíz de la conquista y la mentalidad que conformaron en los inmigrantes españoles.

En adelante la política española fue incierta, accediendo unas veces a la necesidad imperiosa de ocupar efectivamente el territorio, es decir se continuó con el sistema de otorgar privilegios para estimular esta ocupación, e introduciendo, al mismo tiempo, restricciones sobre el empleo de la mano de obra indígena en las labores de minería y en faenas tan penosas como el acarreo de mercancías en los parajes que no permitían el acceso de bestias de carga.

En la Nueva Granada, en donde ni siquiera se intentó una aplicación inmediata de las llamadas "Nuevas Leyes" (existía un estatuto anterior, de 1512, las llamadas 
"Leyes de Burgos") comenzó por eliminarse sin embargo toda eventualidad de resistencia, reduciendo a prisión a los caudillos españoles más influyentes en el interior del país. Pero frente a una amenaza virtual los cabildos, compuestos casi todos en esta primera época por encomenderos, se apresuraron a solicitar ahincadamente que no se aplicaran estas leyes.

Estas peticiones revelan claramente el carácter de la nueva sociedad. Un organismo específicamente urbano solicitaba, en nombre de los conquistadores, que se garantizaran de algún modo los privilegios económicos alcanzados por estos. La corona no podía desoír estas peticiones puesto que con ello se pondría en peligro la suerte de las nuevas ciudades.

La petición más generalizada se refería a las encomiendas que vacaran. Al resistirse la corona a otorgar el privilegio en perpetuidad se buscaba estrechar el círculo de las personas que tuvieran acceso a él. Por eso los conquistadores aspiraban a suceder a los que entre ellos mismos faltaran o murieran. La corona accedió en parte y al disponer los primeros censos de población indígena en 1548 ordenó que se procuraran repartimientos más equitativos entre los pobladores ya asentados, aunque "... ansí mismo se debe dejar alguna parte para que se pueda hacer merced a los que fueren de nuevo, porque de otra manera ya sabéis que, faltándoles esta esperanza, habría pocos que lo hiciesen..."10.

Así, en menos de una generación se preveía que los privilegios de la conquista entrarían en conflicto con las necesidades de una colonización. Aunque desde 1542 la encomienda estuviera destinada a la extinción. Si en la segunda mitad del siglo XVI los conquistadores y sus epígonos lucharon ahincadamente por conservar privilegios, la necesidad de "poblar" el país trajo nuevos inmigrantes con los que había que compartir estos privilegios. Se plantea, naturalmente, la cuestión de saber si los recién llegados constituyeron un factor suficiente de movilidad social o si, por el contrario, se vieron condenados sin remedio a integrarse a la nueva sociedad en una posición subordinada.

En el estado actual de las investigaciones no puede darse una respuesta concluyente a esta pregunta ${ }^{11}$. En algunas regiones la persistencia del poder de los encomenderos es notoria, inclusive hasta el siglo XVIII. Por otro lado, la necesidad

10 Real Cédula de 27 de noviembre de 1548 (Archivo Histórico Nacional de Bogotá [AGN-Colombia], Visitas de Santander, t. 3, f. 692 v.). Esta cédula ordenaba la tasación de los indígenas, es decir, la asignación de lo que debían pagar a los encomenderos como tributo (capitación). La tasación buscaba eliminar pretextos para que los indios fueran ocupados en servicio del encomendero. La orden se reiteró el 14 de septiembre de 1555. Sobre la suerte de las "Nuevas leyes", en la Nueva Granada, $c f$. Friede, Documentos, t. VI, VII y VIII.

11 No parece adecuado considerar a la sociedad española misma como un bloque frente a los estratos mestizo e indígena. Para un punto de vista diferente $c f$. Jaime Jaramillo Uribe, "Mestizaje y diferenciación social en el Nuevo Reino de Granada en la segunda mitad del siglo XVIII”, Anuario Colombiano de Historia Social y de la Cultura (1963). 
de mantener una identidad racial permitió, en muchas ocasiones, el acceso de los recién llegados a la primitiva casta mediante enlaces matrimoniales. Finalmente, las mercedes de tierras "realengas" (baldíos pertenecientes a la Corona) no recayeron necesariamente en los encomenderos y por eso puede pensarse en la existencia de un sector más o menos amplio de población blanca que, sin poseer encomiendas, gozaba de propiedad territorial.

Desde finales del siglo XVI se entabló una lucha sorda entre encomenderos y simples propietarios de tierras que pretendía acceder a la mano de obra indígena. Agotadas las posibilidades económicas de la encomienda se había creado, para estimular a los simples pobladores, el sistema de "conciertos". El indio, teóricamente libre, podía contratar sus servicios o "concertarse". En la práctica intervenía un funcionario real (el corregidor) y los conciertos eran coactivos. Afectaban, de manera ineludible, a una cuarta parte de la población masculina activa o indios sometidos al sistema de capitación, entre los 15 y los 60 años. En todo caso, había que procurarse un mandamiento oficial para obtenerlos, y propietarios y encomenderos luchaban por esta merced ${ }^{12}$. La primera mitad del siglo XVII transcurrió prácticamente en una sucesión interminable de pleitos, en los cuales se alegaba alternativamente la antigüedad del repartimiento o la magnitud de las haciendas. Este último criterio prevaleció finalmente y en 1657 se dispuso que solo haciendas que tuvieran 200 reses o 60 hectáreas sembradas podrían gozar del servicio de "concertados". Al mismo tiempo se ordenaba la efectividad de los salarios y se advertía que se vigilara especialmente a los encomenderos sobre esto $^{13}$.

Con todo, la lucha entre encomenderos y propietarios, es decir, entre un estrato de la sociedad que se apoyaba en privilegios heredados y un sector que tendía, por necesidades prácticas ineludibles, a estabilizar la producción agrícola, no podía alterar en nada un proceso casi fatal de extinción de la población indígena.

En la última década del siglo XVI el gobierno español, consciente del problema mayor de la despoblación indígena, había querido asegurar la conservación de los indios proporcionándoles una posibilidad de asentarse dentro del marco de sus formas tradicionales de vida. Por ello creó los "resguardos", política que en algunas partes iba acompañado con el reagrupamiento de comunidades indígenas en pueblos "a manera de los de los españoles”. Se proveyó que los indios pudieran gozar comunitariamente

12 La limitación a la cuarta parte se hizo en 1657. Hacia esa época el sistema ya se había abolido en México, en virtud de la aparición de la gran hacienda. Cf. Charles Gibson, Los aztecas bajo el dominio español (México: 1967), 229 y ss.

13 Auto de Dionisio Pérez Manrique, presidente de la Audiencia, de 7 de agosto de 1657. Archivo Histórico Nacional de Bogotá [AGN - Colombia], Tierras de Boyacá, t. 17, f. 517 v y ss. Para las hipótesis que se acaban de exponer se ha utilizado una amplia documentación de próxima publicación bajo el título de Fuentes Coloniales para la Historia del Trabajo [Colmenares se refiere al trabajo de recopilación de fuentes para la historia del trabajo en la sociedad colonial que venía realizando junto con Darío Fajardo y Margarita González, y que ya hemos mencionado en nota anterior]. 
de parcelas de tierra, e incorporarse así al sistema económico general. Pero el hecho de que sobre los indios pesaran obligaciones que los separaban periódicamente de sus comunidades (mita agrícola, mita minera) no podía garantizar los resultados de esta política. La despoblación vertiginosa obligó a sucesivas reagrupaciones que iban dejando vacíos los resguardos. Además, la presión exterior de propietarios españoles sobre estos resguardos contribuyó a su desmoronamiento, una lenta agonía que se prolongó hasta mediados del siglo XIX.

Desde muy temprano varias ciudades mineras del occidente del país solicitaron el otorgamiento de franquicias para la importación de esclavos negros. Estas peticiones se reiteraron con mayor fuerza a partir de 1542, ante la amenaza de extinción de la encomienda. Además, si bien se había empleado a los indígenas en los lavaderos de oro, la complejidad de una economía minera exigía la sustitución de este tipo de mano de obra. Se requería complementar la extracción con el abastecimiento de alimentos que se veía amenazado por la alarmante extinción de los cultivadores. Pero la misma fuente de mano de obra que se empleaba en la minería, los esclavos que provenían del África, estaba comprometida. España perdió muy pronto el control exclusivo de este comercio con sus propias colonias, y definitivamente a raíz de la separación de Portugal, en 1640. En adelante tuvo que depender de las potencias marítimas - Holanda, Francia, Inglaterra - a las que se otorgaron sucesivamente privilegios o "asientos" 14 .

La Nueva Granada, sin embargo, gozó de un privilegio por el cual clamaban otras regiones del Imperio. Al menos a partir de 1595. Con anterioridad, en 1565, los propietarios de Popayán solicitaban todavía que se permitiera a los indios trabajar en las minas pues “... son tan estériles las tierras y provincias donde están poblados que no se cogen en ellas trigos ni cebadas ni otras semillas de las que los encomenderos puedan ser aprovechados, ni los naturales de ellas tienen algunos usufructos que poder dar a sus encomenderos ni otros aprovechamientos, si no son los indios que sacan el dicho oro, excepto Santafé y Tunja, en las cuales se siembra y coge trigo y cebada y otras semillas..."15. Ya se había establecido una especialización regional al localizarse las regiones mineras en el occidente del reino y la producción agrícola en los altiplanos, en donde había abundancia de mano de obra indígena. Pero la articulación

14 En 1595 se acordó el primer "asiento" de un monopolio portugués para la trata. Hasta entonces la Casa de Contratación y el Consulado de Sevilla habían guardado celosamente el privilegio. A partir de 1595 los esclavos solo pudieron entrar a América por Cartagena de Indias ( $C f$. Nota 8), hasta 1615, cuando pudieron venderse en Veracruz. $C f$. Rolando Mellafe, La esclavitud en Hispanoamérica (Buenos Aires: 1964).

15 Procuración de las ciudades del Nuevo Reino de Granada y de la Gobernación de Popayán. Archivo Histórico Nacional de Bogotá [AGN-Colombia], Caciques e Indios, t. 26, f. 643 v. Tres años más tarde, una Real Cédula autorizó el trabajo de los indios en las minas de la Nueva Granada. Real Cédula fechada en Madrid el 23 de marzo de 1568. Archivo Histórico Nacional de Bogotá [AGN-Colombia], Caciques e Indios, t. 44, f. 960 r. 
coherente de estos dos sistemas parecía imposible dada la insuperable dificultad de las comunicaciones.

Puede decirse entonces que la minería - centrada en la producción de oro en las provincias del Cauca (incluido el Chocó) y de Antioquia ${ }^{16}$ - se desarrolló librada a sus propios recursos y a centros de abastecimiento insuficientes. Ambas regiones mineras sufrieron un proceso peculiar, tan característico para cada uno que fue capaz de imprimir un sello y de fijar las pautas de su desarrollo futuro.

En la provincia del Cauca, que pudo articularse en alguna forma a las posibilidades agrícolas de la Audiencia de Quito (inclusive hizo parte de su jurisdicción político-administrativa), se dio una concentración inusitada de recursos. La alianza del poder político con el prestigio familiar y la riqueza permitió la formación de verdaderas empresas que culminaron con el establecimiento de una Casa de la Moneda en Popayán. Algunos mineros en Nóvita y Tadó (Chocó) poseían cuadrillas de 500 esclavos a comienzos del siglo XVIII ${ }^{17}$, una posibilidad financiera inaudita y que aún podía acrecentarse en virtud de asociaciones familiares.

El contraste con la región antioqueña no puede ser más marcado. Allí la empresa minera se caracterizó por la inestabilidad permanente ${ }^{18}$, por la movilidad constante de los empresarios, casi siempre individuales y dentro de una escala de productividad reducida. Se ha subrayado con suficiente nitidez este fenómeno de la aparición de empresarios autónomos ${ }^{19}$ que crearon las condiciones de movilidad social excepcionales, dentro del contexto de Nueva Granada. Dificultades de abastecimiento, técnicas inapropiadas para explotaciones a largo plazo y pobreza de los yacimientos empujaban a los pequeños productores hacia nuevas prospecciones. Esta movilidad se comunicó a otros estratos sociales (comerciantes, principalmente) y diversificó los centros urbanos en los cuales no era posible una concentración de poder financiero o de control político excepcionales. Antioquia, sin embargo, vino a ser víctima de la desarticulación de la economía minera con el sector agrícola y existen testimonios de crisis en el siglo XVI-

16 La provincia de Pamplona conoció un auge pasajero de la minería hasta las primeras décadas del siglo XVII.

17 Archivo Histórico Nacional de Bogotá [AGN-Colombia], Caciques e Indios, t. 23, f. 967r. Contiene un expediente que ilustra las condiciones de la explotación minera en Nóvita y Tadó.

$18 \quad C f$. la obra ya clásica de Vicente Restrepo, Estudio sobre las minas de oro y plata en Colombia (Bogotá: 1952). Restrepo subraya los sucesivos desplazamientos de los centros mineros antioqueños. Los tomos 63 a 65 del Archivo Histórico de Medellín registran la existencia entera del real de Minas de Guamoco (1600-1703), cuyo abastecimiento se hacía desde Mompós. A pesar de la riqueza material no existe un estudio reciente (el de Restrepo data del siglo pasado) sobre la economía minera colombiana.

19 Existen estudios de conjunto del fenómeno antioqueño: James Parsons, La colonización antioqueña en el occidente de Colombia (Medellín: 1950); Eugene Havens, Támesis, estructura y cambio (Bogotá: 1966); Everett Hagen, On the Theory of Social Change (Illinois: 1962). Contra las tesis centrales de Haven, Frank Safford, "Significado de los antioqueños en el desarrollo económico colombiano", Anuario Colombiano de Historia Social y de la Cultura (1967). Una síntesis de los argumentos en la monografía de Álvaro López T., Migración y cambio social en Antioquia durante el siglo XIX [en mimeógrafo] (Bogotá: 1968). 
II. Con todo, estas dificultades propiciaron un movimiento colonizador sin precedentes que se inició a finales de la Colonia y culminó en la primera década de este siglo [XX].

La excesiva especialización de la mano de obra negra restringió el establecimiento de plantaciones que solo podían aprovechar los excedentes de esclavos que proporcionaban crisis periódicas de la minería. Esta restricción condujo fatalmente a un tipo de explotación cuyo incremento podía pasarse de la mano de obra indígena, cada vez más escasa, y de la mano de obra esclava, demasiado costosa: la ganadería. Para esta podía pensarse en el empleo de mestizos, cada vez más abundantes, para los cuales el paternalismo de la corona española no había previsto un estatuto de "protección” legal o de capitación. La ganadería permitía, además, el uso extensivo de tierras obtenidas mediante mercadeos reales, "composiciones" (compras a la corona), o simple despojo de los resguardos indígenas. La ganadería no tuvo en la Nueva Granada - con excepción de la región de los Llanos orientales - el carácter de una economía de frontera móvil sino que vino a llenar el vacío que no podía ocupar la economía de plantación, por un lado, y a procurar el abastecimiento de las regiones mineras, por otro. Este tipo de empresa creció a expensas de la agricultura tradicional, cuyos recursos de mano de obra eran cada vez más escasos, y permitió la formación de latifundios en los profundos valles interandinos.

Una de las dificultades con las que tropieza un conocimiento siquiera aproximado de la economía colonial hispanoamericana se origina en el énfasis excesivo con que se vincula al proceso de desarrollo económico europeo ${ }^{20}$.

Este énfasis se apoya en dos perspectivas, valiosas sin duda, pero que solo han contribuido a distorsionar o a simplificar demasiado el problema. En todo caso constituyen un marco demasiado general e influyen escasamente en el conocimiento de ciertas peculiaridades de la contrapartida americana del Imperio español. En primer término, consideraciones nacidas de la observación más obvia de una economía minera cuya producción se destinaba, en último término, a nutrir la circulación monetaria europea. Luego, el estudio detallado de las presiones ejercidas sobre la periferia del Imperio por potencias marítimas como Holanda, en el siglo XVII, eventualmente Francia y definitivamente Inglaterra.

Se supone que la debilidad del Imperio afectaba por igual a todas sus partes, aun si se admite una cierta prosperidad en las colonias, que contrastaba extrañamente con la debilidad de la metrópoli. La ineptitud manufacturera española abría una brecha dentro del sistema que permitía la participación de otras potencias mediante un

20 La pobreza de los estudios de historia económica regional se refleja en los manuales, aun los mejores, como el de Clarence H. Haring, The Spanish Empire in America (Oxford: Oxford University Press, 1947) y el de J. H. Parry, The Spanish Seaborne Empire (Londres: 1966). Hasta el punto de que Parry cita como ejemplo excepcional de asentamiento agrario en Hispanoamérica la región antioqueña. De otro lado la historia calcada en el patrón nacionalista decimonónico no ha podido aportar sino observaciones superficiales. 
comercio de contrabando desembozado. Las reformas borbónicas, llevadas a cabo en la segunda mitad del siglo XVIII, apuntaron precisamente a liberalizar el sistema, aliviando al imperio de esas presiones, en un intento desesperado de conservar el dominio político de las colonias.

Con todo, no parece correcto enjuiciar el sistema establecido por la Casa de Austria desde un punto de vista "nacional" cuando fue concebido como una totalidad" ${ }^{21}$. Hasta las reformas borbónicas el Imperio había constituido una unidad cerrada de economías complementarias. Cada reino poseía una función o una forma de especialización que podía desarrollar siempre y cuando no comprometiera al sistema entero. En torno a la riqueza minera del Perú, por ejemplo, el reino de Chile, las provincias del reino de La Plata y la Audiencia de Quito constituían una fuente de abastecimientos agrícolas, procuraban los medios de transporte y encontraban un mercado suficiente para géneros industriales.

Las provincias del sur de la Nueva Granada contribuyeron a este complejo. Otras regiones, como se ha visto, ni aun pudieron articularse entre sí. Los altiplanos del centro del país limitaron entonces su actividad al aprovechamiento de las ciudades, particularmente Santafé y Tunja, y eventualmente la plaza fuerte de Cartagena. Pero a pesar de todos los esfuerzos por activar la producción de cereales con el fin específico de abastecer esta plaza ${ }^{22}$, siempre resultaron más baratos los granos ofrecidos por las colonias inglesas, comercio al que los criollos de Cartagena, y aun del interior, se mostraron siempre favorables, puesto que significaba una oportunidad de recibir buena cantidad de artículos de contrabando.

Parece inútil, sin embargo, localizar en un sector (en este caso, el de los comerciantes) la responsabilidad de la ruptura con España. El complejo criollo de intereses no conoció una diversificación perceptible debido al carácter "colonial" de la economía, es decir, a la participación simultánea del estrato dominante en una variedad de empresas que alimentaban la actividad comercial. El comercio intercolonial, no obstante, jamás había parecido suficiente para colmar la aspiración de los criollos. Las mismas reformas ilustradas abrieron el camino a la desvertebración característica de las economías latinoamericanas desde entonces. Era evidente desde hacía mucho tiempo que España no podía brindarse sino como intermediaria -a través del monopolio sevillano- de comerciantes europeos, con los que parecía preferible tratar directamente, ya fuera a través del contrabando o de franquicias legales.

21 Estudios de economía regional como el de Arcila Farias para la economía del cacao en Venezuela tienden a confirmar este punto de vista. Su primera expresión, un poco polémica, en Ricardo Cappa, Estudios críticos acerca de la dominación española en América. 19 vols. Cf. especialmente vols. V y VI.

22 A este problema aluden frecuentemente las Relaciones de Mando de los virreyes en el siglo XVIII. [Colmenares editaría muchos años después las relaciones de mando que menciona aquí, bajo el título de Relaciones e informes de los gobernantes de la Nueva Granada, tres tomos (Bogotá: Fondo de Promoción de la Cultura del Banco Popular, 1989)]. 
En esencia, los rasgos de la economía colonial reformada se conservaron hasta mucho después de la independencia política. Los hombres que intervinieron en estas luchas (1810-1825) eran los herederos del pensamiento ilustrado, o al menos podían disfrazar con una retórica de "Las Luces" lo que ha llamado un historiador francés "el complejo criollo de la frustración" "23. Un aparente rechazo de las formas tradicionales no podía afectar para nada el andamiaje entero de una sociedad cuyo dominio reposaba en manos de los "libertadores".

Y ni aun dentro de este grupo - restringido - pueden descubrirse antagonismos sobre los que pudiera apoyarse una dinámica social. Así, los intereses del estamento criollo de comerciantes no se distinguían radicalmente de otros intereses. Cualquier forma de riqueza o de prestigio se alimentaba en las desigualdades heredadas. La declamación liberal agitó ocasionalmente ideas relativas a la esclavitud e inclusive procuró una igualdad republicana para los indígenas (unos 100.000) que aún subsistían. Pero al mismo tiempo se aceleró el proceso de desintegración de los resguardos, incompatibles con una legislación que desdeñaba el paternalismo.

Las mayores preocupaciones de la nueva sociedad se manifestaban en interminables alegatos filosófico-jurídicos destinados a legitimar el nuevo orden o a evocar las promesas de la Ilustración dieciochesca ${ }^{24}$. Un cierto optimismo inicial permitió cristalizar empresas respecto de las cuales el Estado asumió una política abiertamente proteccionista $^{25}$. Pero estos primeros intentos de liberación económica se vieron frustrados muy pronto debido, en parte, a la excentricidad con respecto al sistema entero, en parte, a las condiciones de inestabilidad política que provocó la ruptura con España.

Además, la república había nacido cargada de obligaciones hacia generosos inversionistas ingleses y el Estado atravesó por serias dificultades financieras durante las primeras décadas de su existencia ${ }^{26}$. Los empréstitos forzosos, originados en necesidades militares, creaban un clima de desconfianza insuperable y constituían una fuente permanente de resentimiento político.

El ejército, una de las últimas creaciones borbónicas, vino a insertarse en medio de una sociedad de formación escolástica, de comerciantes y latifundistas, después de las guerras de Independencia. En algunas ocasiones a través de los rangos, sirvió

23 Pierre Chaunu, "Interprétation de l'Independence de l'Amérique Latine" (Extrait du Bulletin de la Faculté de Lettres de Strasbourg. Mai-Juin 1963, 403-421). Según Mr. Chaunu, "l’Independence politique a été payée d'un renforcement des structures sociales de domination, à l'intérieur, [et] d"un renforcement, au dehors, des liens de dépendance économique...".

$24 \quad$ Hay ejemplos numerosos de esta literatura, de la que se nutrió la generación de la Independencia. Los más notables Pedro Fermín de Vargas, Pensamientos políticos y memoria sobre la población del Nuevo Reino de Granada (Bogotá: 1944); Francisco José de Caldas, Semanario; Luis Azuola y Jorge Tadeo Lozano, Correo Curioso, erudito, económico y mercantil; Antonio Nariño, Bagatela (varias ediciones). Cf. Luis Ospina Vásquez, Industria y protección en Colombia (Bogotá: 1955).

26 Un análisis imparcial de este periodo en David Bushnell, El régimen de Santander en la Gran Colombia (Bogotá: 1966). Según Bushnell, “... ninguna crisis política podía competir con el estado desastroso de las finanzas colombianas”. (p. 95). 
como instrumento de promoción social, pero en líneas generales pudo asimilar su estructura al carácter general de la sociedad. En cambio sí construyó una fuente permanente de malestar político puesto que los conflictos locales siempre podían encontrar a mano un caudillo con un exceso de ambiciones.

Solo a mediados de la centuria pudieron expresarse a cabalidad aspiraciones que buscaban crear un nuevo orden, rechazando de una manera nítida la gerencia colonial $^{27}$. Con todo, estas aspiraciones resultaron un poco contradictorias. Quería buscarse un fundamento sólido de prosperidad económica para una burguesía naciente y al mismo tiempo hacer participar del poder político a una masa creciente de granadinos mucho menos afortunados. Quería utilizarse el poder del Estado mismo como herramienta al tiempo que se propugnaba por un sistema federal. Un sustrato ideológico liberal parecía operar en el vacío, a pesar de la generosidad de sus enunciados, creando un abismo ostensible entre los hechos y las palabras. Se tendía a subordinar, en suma, exigencias de un orden social al movimiento social espontáneo, suponiendo que los intereses económicos podían combinarse armónicamente con una mínima intervención del Estado.

Así, la tendencia hacia el federalismo coincidió con la supresión del monopolio del tabaco que, al igual que otras actividades económicas, el Estado español había controlado como recurso fiscal. La Nueva Granada, que en el periodo colonial no había desarrollado una economía de plantación, tuvo oportunidad por primera vez de acceder al mercado mundial con productos tropicales.

En términos de comercio internacional es posible que la sustitución de una economía minera por una comercialización de la agricultura no haya significado un cambio demasiado radical. En el interior del país, sin embargo, propició transformaciones radicales. La abolición de la esclavitud, entre otras. Además, el tabaco constituyó el primer eslabón de una cadena de estos productos tropicales que incorporaron a la explotación económica las tierras de las vertientes de los Andes, hasta entonces inutilizadas. Este proceso de colonización interior contribuyó a la ruptura de vínculos tradicionales entre los peones de las haciendas de los altiplanos, permitiendo que una población anquilosada participara activamente en una forma de empresa y aun en una elaboración rudimentaria de productos a gran escala ${ }^{28}$.

En el proceso se sacrificaron otras alternativas, puesto que en el estaban interesados sobre todo comerciantes apegados a las doctrinas del libre cambio. A sus ojos

27 He sustentado más ampliamente estos puntos de vista en un libro que abarca el periodo 1848-1854. $C f$. Partidos políticos y clases sociales (Bogotá: 1969). Otros puntos de vista en Luis Eduardo Nieto Arteta, Economía y cultura en la historia de Colombia (Bogotá: 1962).

28 Ibid., 241 y ss. Este autor atribuye una importancia excesiva al desarrollo manufacturero de la región nororiental colombiana. La evolución de este desarrollo habría sido abolida por la política del librecambio, adoptada a mediados del siglo XIX. Son muy dudosas, sin embargo, las posibilidades técnicas de empresas artesanales de origen colonial (obrajes). No existe, infortunadamente, un estudio notorio sobre este tipo de empresas. 
parecía evidente que la misma Providencia señalaba el destino de las naciones en materia económica al procurarle recursos que imponían una especialización internacional del trabajo. La Nueva Granada era un país eminentemente agrícola, según los teóricos, y debía continuar siéndolo. Competir en otro sentido significaba procurarse capitales y avances tecnológicos inaccesibles. 